\title{
Evaluation of Marginal Gap / Fit of Zirconia Copings \& Full Contoured Monolith Zirconia Crowns (CAD / CAM) - A Comparative In-Vitro Study
}

\author{
Liya Zacharias ${ }^{1}$, Rajesh Shetty ${ }^{2}$, Mohammad Zahid ${ }^{3}$ \\ 1, 2,3 Department of Prosthodontics, Yenepoya Dental College, Mangalore, Karnataka, India.
}

\section{ABSTRACT}

\section{BACKGROUND}

Inadequate marginal fit of fixed restorations leads to plaque accumulation, recurrent caries and periodontal problems. The purpose of this experimental study is to evaluate and compare the marginal fit/gap of computer-aided design and computeraided manufacturing (CAD/CAM) fabricated zirconia copings and zirconia full contoured monolith crowns fabricated on type IV gypsum die having a definite cement spacer thickness of $0.05 \mathrm{~mm}$.

\section{METHODS}

This is an in-vitro experimental study carried out from November 2018 to November 2019. A master stainless steel die was used to make 52 type IV die stone models which were randomly divided into 2 groups of 26 samples each. Group 1: zirconia copings and group 2: zirconia monolith full contoured crowns. These restotations were fabricated using CAD/CAM. The marginal gap of each zirconia copings and zirconia full contoured crowns was assessed using scanning electron microscopic analysis on four different pre-marked points (GEMINI SEM 500; ZEISS). Observations were tabulated and analyzed statistically. Independent t-test was used to compare the measurements between zirconia copings \& zirconia monolith crowns.

\section{RESULTS}

The least marginal gap observed was for group 2 (zirconia full contoured crown) with a mean value of $29.88 \pm 9.16 \mu \mathrm{m}$ while that of group1 (zirconia coping) was $73.64 \pm$ $28.13 \mu \mathrm{m}$. There was a statistically significant difference in the measurements between zirconia copings and zirconia full contoured monolith crowns (P - value < 0.001). There was statistically significant difference in each side of zirconia monolith crowns when compared to the corresponding side of zirconia copings (P - Value < 0.001).

\section{CONCLUSIONS}

CAD/CAM milled full contoured zirconia crowns showed least marginal discrepancy when compared to zirconia copings. All samples had marginal gap within the clinically acceptable range of $120 \mu \mathrm{m}$.

\section{KEY WORDS}

Monolith, Zirconia Crowns, Zirconia Copings, Full Contoured Crowns, CAD-CAM
Corresponding Author: Dr. Rajesh.Shetty, Professor,

Department of Prosthodontics, Yenepoya Dental College, Mangalore - 575018, Karnatama, India.

E-mail:dr_rajeshshetty@yahoo.co.in

DOI: $10.14260 / j e m d s / 2021 / 311$

How to Cite This Article:

Zacharias L, Shetty R, Zahid M. Evaluation of marginal gap / fit of zirconia copings \& full contoured monolith zirconia crowns (CAD / CAM) - a comparative in-vitro study. J Evolution Med Dent Sci 2021;10(20): 1483-1488, DOI: $10.14260 /$ jemds/2021/311

Submission 06-01-2021, Peer Review 14-03-2021, Acceptance 20-03-2021, Published 17-05-2021.

Copyright (c) 2021 Rajesh Shetty et al. This is an open access article distributed under Creative Commons Attribution License [Attribution 4.0 International (CC BY 4.0)] 


\section{BACKGROUND}

Achieving aesthetic and clinically ideal restorations has been the aim of dental restorative practitioners in the ever evolving field of dentistry. Porcelain fused to ceramic restorations have long been in use in fixed prosthodontics due to their excellent durability. The aesthetic demands for metal-free, more biocompatible restorations have directed material research and development towards all ceramics materials. Among the currently available high strength zirconia all ceramic cores, yttria-stabilized zirconia stands out in terms of its compressive strength, flexural strength, fracture toughness, hardness and translucency.

It was developed as a substitute to metal framework especially in posterior fixed partial dental prosthesis wherein the main concern was strength. Zirconia undergoes a phenomenon called transformation toughening which contributes to its remarkable strength. ${ }^{1}$ Shetty et al. ${ }^{2}$ in their study, demonstrated that modifications in design of posterior framework can improve the flexural strength of yttrium based zirconia. Zirconia can be easily fabricated from presintered blocks, which are milled using CAD/CAM system.

The longetivity of metal free restorations depends on the bonding properties of the all ceramic material to natural teeth. It is also influenced by its marginal and internal fit. Inaccurate marginal fit is responsible for plaque retention, microleakage and cement breakdown. ${ }^{3}$ All these factors lead to a deleterious effect on the periodontium thereby affecting the health of the underlying abutments. ${ }^{4}$ Literature has shown that the marginal discrepancy of ceramic crowns is influenced by various factors such as tooth preparation geometry, type of luting cement, and factors related to dental laboratory fabrication techniques. ${ }^{5}$

M.K Ji et al. in his study reported that the marginal gap for presintered yttrium stabilized zirconium dioxide all ceramic crown was in the range of $91-118 \mu \mathrm{m}$ for shoulder margin and $84-109 \mu \mathrm{m}$ for a deep chamfer margin. ${ }^{6}$ May et al. found that the mean marginal gap and occlusal gap of procera all ceramic crowns were in the range of 64-74 $\mu \mathrm{m} .{ }^{7}$ Weaver et al. reported that the marginal gap of castable all ceramic crown was 82 $\mu \mathrm{m} .{ }^{8}$ The purpose of this study is to evaluate and compare the marginal gap/fit of CAD/CAM fabricated zirconia copings and zirconia fully contoured monolith crowns.

\section{Objectives}

1. To evaluate the marginal gap/fit of zirconia copings fabricated using CAD/CAM.

2. To evaluate the marginal gap/fit of full contoured monolith zirconia crowns fabricated using CAD/CAM.

3. To compare the marginal gap/fit of zirconia copings and full contoured monolith zirconia crowns fabricated using CAD/CAM

\section{METHODS}

This is an in-vitro experimental study carried out from November 2018 to November 2019 in the CAD-CAM lab, Department of Prosthodontics, Yenepoya Dental College, Mangalore, Karnataka.

\section{Armamentarium}

- Metallic die

- Dappen dish

- Vacuum mixer

- Investment vibrator (Confident)

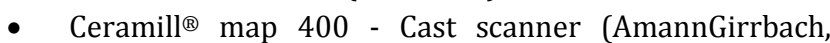
Austria)

- $\quad$ Ceramill ${ }^{\circledR}$ mind - Computer aided designing software (AmannGirrbach, Austria )

- Ceramill ${ }^{\circledR}$ motion 2 - Computer aided milling (AmannGirrbach, Austria)

- $\quad$ Ceramill ${ }^{\circledR}$ therm - Sintering (AmannGirrbach, Austria)

- Scanning electron microscope (GEMINI SEM 500; ZEISS, Germany)

\section{Materials}

1. Ceramill ${ }^{\circledR}$; (Zirconia blank - ZI) - Zirconia coping (AmannGirrbach, Austria)

2. Ceramill ${ }^{\circledR}$; (Zirconia blank - Zolid) - Zirconia full contoured crowns (AmannGirrbach, Austria)

1. Polyvinylsiloxane (Aquasil soft putty/regular set; Dentsply Caulk, USA)

2. Type IV dental stone (Elite rock; Zhermack, sandy brown, Italy)

\section{Preparation of the Metallic Die}

A stainless steel master die of maxillary $1^{\text {st }}$ bicuspid was made according to the specifications originally described by Bailey et al. (1988) ${ }^{9}$ with a vertical dimension of $12 \mathrm{~mm}$ from the cavosurface line angle to the occlusoaxial line angle, a diameter of $13 \mathrm{~mm}$ at the cavosurface line angle with convergence angle of $6^{\circ}$ providing a diameter of $9 \mathrm{~mm}$ at the occlusal end of the die with a shoulder width of $1 \mathrm{~mm}$. A flat surface was prepared on one side which was labelled as buccal surface. This will help us in easy identification of the buccal, lingual, mesial and distal surfaces thereby helping us to orient the copings and crowns under the scanning electron microscope. The flat surface also helps as it has anti-rotation feature. The base of the master die has four sides. At four predetermined points, a vertical inscription was made wherein the measurements were calculated.

\section{Impression of the Metallic Die}

Impression was made using Polyvinyl siloxane impression material (Aquasil soft putty / regular set; Dentsply Caulk).The impression material was manipulated and loaded into a dappen dish. The metallic die was pressed into the dappen dish and allowed to set, according to the manufacturer's recommendation.

\section{Preparation of the Type IV Gypsum Die}

Type IV dental stone (elite rock; zhermack, sandy brown) was mixed and poured into the impression using a vibrator and allowed to set according to manufacturer's recommendations. The above mentioned procedure was repeated to secure $52 \mathrm{die}$ models. The 52 die models were grouped into 2 groups, each group comprising of 26 die models each. 


\section{Fabrication of CAD/CAM Zirconia Copings}

Ceramill Amann Girbach, a dental CAD / CAM system, was used to fabricate the 26 zirconia copings used in this study. All 26 die models were scanned using Ceramill scanner. Scanned data was then converted into CAD data. Copings for all-ceramic crowns was designed using the dental wings supported by Ceramill software. A definite cement space thickness of $0.05 \mathrm{~mm}$ was provided. Thickness of all 26 all ceramic copings was designed to be $0.7 \mathrm{~mm}$. Once the copings were milled, they were sintered in Ceramilltherm; Amann Girrbach.

\section{Fabrication of Zirconia Monolith Full Contoured Crown}

Ceramill Amann Girbach, a dental CAD/CAM system, was used to fabricate the 26 zirconia monolith full contoured crowns used for this study. All the 26 die models were scanned using Ceramill scanner. Scanned data was then converted into CAD data. Full contoured all ceramic monolith zirconia crowns were designed using the dental wings supported by Ceramill software. A definite cement space thickness of $0.05 \mathrm{~mm}$ was provided. The internal zirconia monlith crown thickness was designed to be $0.7 \mathrm{~mm}$. Once the crowns were milled, they were sintered in Ceramilltherm; Amann Girrbach.

Marginal gap of each zirconia copings and zirconia monolith crowns was assessed using scanning electron microscopic analysis on four different pre-marked points. Two measurements were taken on each side at pre-determined points. The average of the two values were calculated to get the mean of one pre-determined point and the average of the four pre-determined points were taken to know the mean marginal gap of the respective dies. All measurements were made at $200 \mathrm{X}$ magnification and at $5.00 \mathrm{KV}$.

\section{RESULTS}

All the 52 samples were measured with scanning electron Microscope. Four vertical measurements were made at predetermined points. The measurements were made with the help of ZEISS Atlas 5 software. The mean of two values at a predetermined point was taken as the mean marginal gap for one side and the mean of the 4 pre-determined points were taken as the mean marginal gap of that respective die. Observations were tabulated and analysed statistically.

Two samples independent t-test was used to compare the mean score of marginal gap measurements between zironia full contoured crowns and zirconia copings for zirconia full contoured crowns. The mean difference from group 1 to group 2 was $43.77 \mu \mathrm{m}$ with standard error of difference was 5.88 , with this difference; the t-test statistics was concluding statistically significance difference at $1 \%$ level of significance and at $80 \%$ power of the test.

- $\quad$ The mean marginal gaps varied within a range of 15.31 $\mu \mathrm{m}$ to $47.3 \mu \mathrm{m}$.

- The marginal gaps between the values of point 1 varied from $16.43 \mu \mathrm{m}$ to $54.46 \mu \mathrm{m}$.

- The differences in the marginal gaps in point 2 ranged from $9.68 \mu \mathrm{m}$ to $47.12 \mu \mathrm{m}$.

- Differences in the marginal gaps in point 3 ranged from $8.18 \mu \mathrm{m}$ to $52.91 \mu \mathrm{m}$.
- The marginal gaps between point 4 varied within a range of $5.87 \mu \mathrm{m}$ to $44.63 \mu \mathrm{m}$

\section{For Zirconia Copings}

- $\quad$ The mean marginal gaps varied within a range of 37.58. $\mu \mathrm{m}$ to $118.2 \mu \mathrm{m}$.

- $\quad$ The marginal gaps between the values of point 1 varied from $25.03 \mu \mathrm{m}$ to $119.8 \mu \mathrm{m}$.

- The differences in the marginal gaps in point 2 ranged from $35.32 \mu \mathrm{m}$ to $119.1 \mu \mathrm{m}$.

- Differences in the marginal gaps in point 3 ranged from $29.27 \mu \mathrm{m}$ to $119.34 \mu \mathrm{m}$.

- The marginal gaps between points 4 varied within a range of $27.92 \mu \mathrm{m}$ to $119.67 \mu \mathrm{m}$

\begin{tabular}{|c|c|c|c|c|c|}
\hline Group & $\mathbf{N}$ & $\begin{array}{c}\text { Mean } \pm \text { SD } \\
(\mu \mathrm{m})\end{array}$ & $\begin{array}{c}\text { Mean } \\
\text { Difference }\end{array}$ & $\mathbf{t}$ & P Value \\
\hline $\begin{array}{l}\text { Coping } \\
\text { Crown }\end{array}$ & $\begin{array}{l}26 \\
26 \\
\end{array}$ & $\begin{array}{l}73.64 \pm 28.13 \\
29.88 \pm 9.16\end{array}$ & 43.77 & 7.542 & $<0.0^{*}$ \\
\hline & Zirco & $\begin{array}{l}\text { ble 1. Mean o } \\
\text { Full Contou }\end{array}$ & $\begin{array}{l}\text { Marginal Gal } \\
\text { d Crowns \& }\end{array}$ & $\begin{array}{l}\text { etwee } \\
\text { bing (i }\end{array}$ & \\
\hline
\end{tabular}

- $\quad$ The mean marginal gap in the zirconia coping was 73.64 $\pm 28.13 \mu \mathrm{m}$ while that in zirconia full contoured crowns was $29.88 \pm 9.16 \mu \mathrm{m}$.

- The mean observed difference between zirconia full contoured crowns and zirconia copings was $43.77 \mu \mathrm{m}$. The $\mathrm{t}$-value was $7.542 \&$ the $\mathrm{P}$ value was $<0.001$ which was statistically significant.

Comparison of Marginal Gap between Zirconia Coping \& Zirconia Crown on All 4 Sides (in $\mu \mathrm{m}$ )

- The mean value of zirconia coping on side A was 74.3254 while that of zirconia crown was 32.6088 .

- The mean value of zirconia coping on side B was 72.3531 while that of zirconia crown was 28.6546.

- $\quad$ The mean value of zirconia coping on side $C$ was 73.7854 while that of zirconia crown was 29.0781.

- $\quad$ The mean value of zirconia coping on side D was 74.1119 while that of zirconia crown was 28.5550

Comparison of Measurements between Crown and Coping on Each Side Using Independent tTest

- There was a statistically significant difference between side A of zirconia full contoured crown when compared to side A of zirconia coping $(\mathrm{t}=6.396, \mathrm{P}<0.001 \&$ mean difference $=41.71654$ ) .

- There was statistically significant difference between side $B$ of zirconia full contoured crown when compared to side $\mathrm{B}$ of zirconia coping $(\mathrm{t}=7.687, \mathrm{P}<0.001 \&$ mean difference $=43.69846$ ).

- There was statistically significant difference between side $\mathrm{C}$ of zirconia crown when compared to side $\mathrm{C}$ of zirconia coping $(t=7.317, \mathrm{P}<0.001$ \& mean difference $=7.317)$.

- There was statistically significant difference between side D of zirconia crown when compared to side D of zirconia coping $(\mathrm{t}=6.951, \mathrm{P}<0.001 \&$ mean difference $=$ 45.55692). 
The Results of the Statistical Analysis Were as

Follows

1. There was a significant statistical difference in measurements between zirconia crown and zirconia coping $\mathrm{P}<0.001$.
2. There was a significant statistical difference in each side of zirconia crown when compared to the corresponding side of zirconia coping $\mathrm{P}<0.001$.
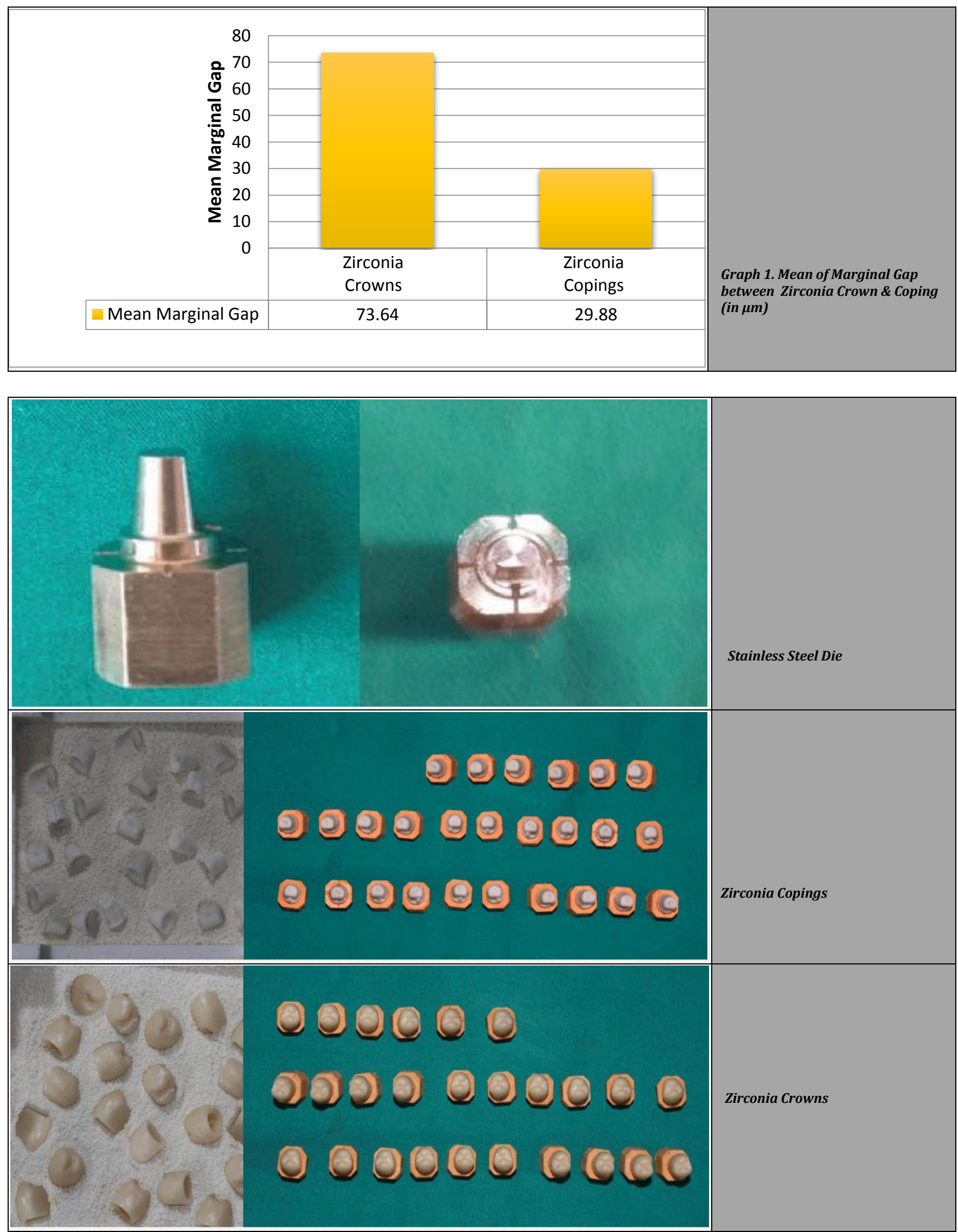


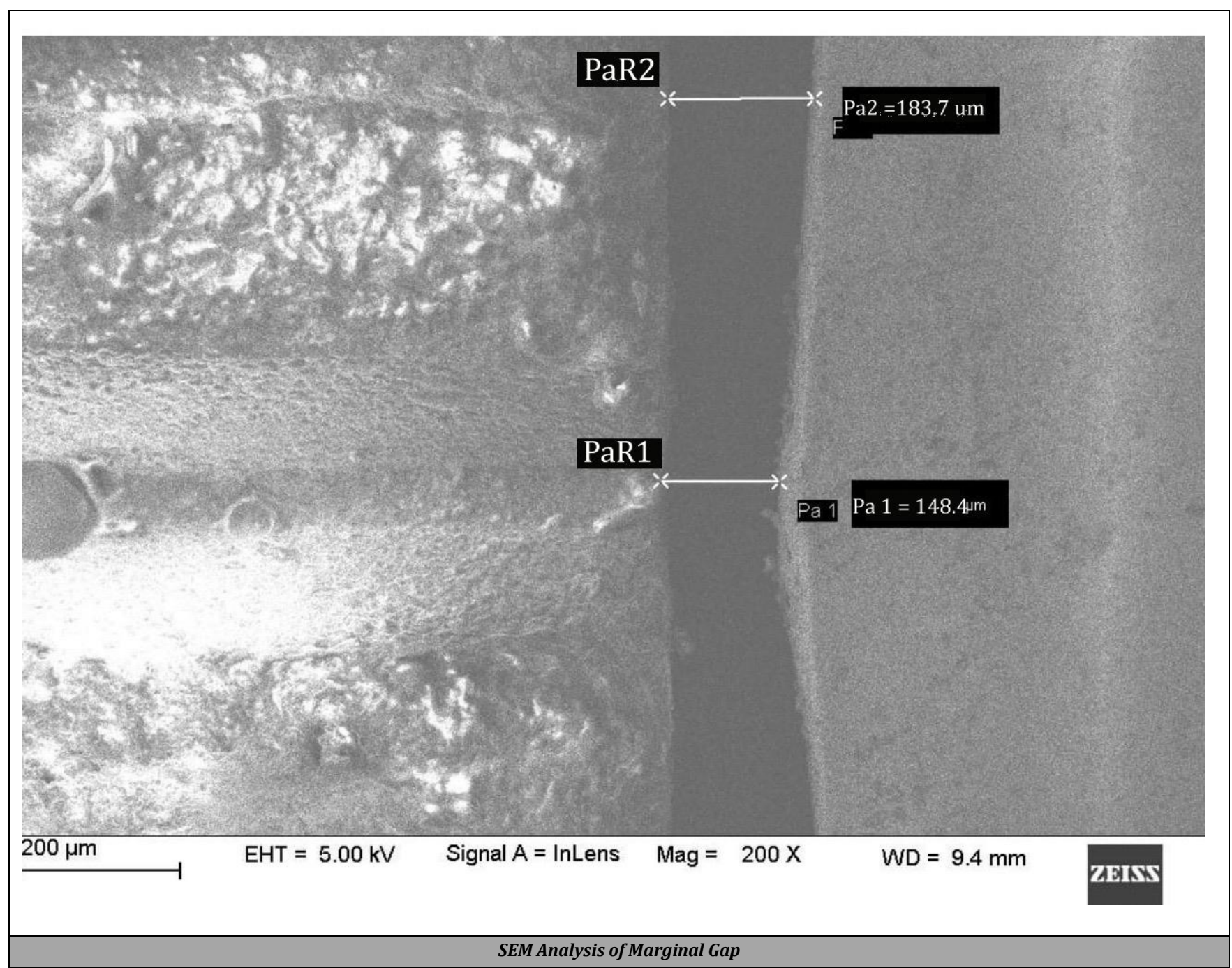

\section{DISCUSSION}

This experimental study was done to evaluate and compare the marginal fit/gap of CAD/CAM fabricated zirconia copings \& zirconia full contoured monolith crowns.The study required the fabrication of a stainless steel master die as proposed by Bailey et al. ${ }^{9}$ Impression of the master die was made by using Polyvinylsiloxane impression material. The impression was poured with type IV dental stone to obtain 52 die models, which were then randomly divided into 2 groups of 26 die models each. Ceramill Amann Girbach, a dental CAD / CAM system, was used to scan and mill 26 zirconia copings \& 26 zirconia full contoured monolith crowns for this study.

The marginal gap of each zirconia copings and zirconia monolith crowns was assessed using scanning electron microscopic analysis on four different pre-marked point. The marginal gap of each sample was observed, tabulated and analysed statistically. Independent t-test was used to compare the measurements between zirconia copings and zirconia monolith crowns.

The results of this study showed that the mean marginal gap of CAD/CAM zirconia copings was $73.64 \pm 28.13$. The results of this study were in accordance with the findings of the study conducted by Bindl A et al. (2005). ${ }^{10}$ The mean values of the marginal fit/gap of zirconia copings was within the clinically acceptable limit of $120 \mu \mathrm{m} .{ }^{11}$
There was a large marginal gap among the zirconia copings which could be due to the shrinkage error that occurs during the sintering process due to the low material volume near the margins. ${ }^{12}$ The marginal gaps of CAD/ CAM-generated zirconia copings in other studies ranged from 24 to $110 \mu \mathrm{m}$. Another reason for the higher marginal discrepancy of the zirconia copings may be due to a phenomenon called point clouds in the scanning process. Due to the high resolution scanner of the computer system, any point irregularities known as point clouds obtained in scanning were transformed into a smooth, continuous surface by the software. This could lead to imperfections in the restoration. ${ }^{13}$

The marginal gap of zirconia monolith crowns in this study was $29.88 \pm 9.16 \mu \mathrm{m}$. These findings were similar to the results obtained by Nakamura et al. (2003) ${ }^{14}$ \& Kokubo Y et al. (2011). ${ }^{15}$ The mean values of the marginal fit/gap of full contoured zirconia monolith crowns was within the clinically acceptable limit of $120 \mu \mathrm{m}$. The difference among the marginal fit/gap of full contoured monolith crowns may be due to the errors in scanning as well as the material shrinkage of partial sintered zirconia that happens during the final sintering stage.

The reason for comparing the zirconia coping accuracy without veneering and full contoured monolith crown was that the copings can reveal the true fit of the restoration. ${ }^{16}$ Also, the values that were obtained in this study showed that zirconia monolith full contoured crowns were better than zirconia copings. Varying results for the zirconia fully 
contoured crowns and copings may have been due to the difference in the procedural steps during CAD/CAM processing namely scanning, design, and milling. The results clearly showed that the marginal fit of zirconia monolith full contoured crowns were much better when compared to the marginal fit of zirconia copings.

\section{CONCLUSIONS}

- In this in-vitro study, the marginal gap of CAD/CAM zirconia copings \& zirconia full contoured monolith crowns were evaluated and compared as these are the most commonly used materials for fabricating crowns and fixed partial dentures (FPD).

- The mean marginal gap among zirconia copings was $73.64 \pm 28.13 \mu \mathrm{m}$ while that of zirconia monolith full contoured crowns was $29.88 \pm 9.16 \mu \mathrm{m}$

- The results of this study showed that it is always better to restore a tooth with monolithic zirconia full contoured crown rather than zirconia coping with ceramic veneering.

\section{Limitations of the Study}

The horizontal marginal gap, absolute marginal gap and internal gap were not measured which can also determine the longevity of the prosthesis. The finish lines \& the placement of margins could also have an impact on the marginal fit/gap in the crowns \& copings. Since, the influence of the veneering procedure was not evaluated, it may or may not reflect the final marginal fit of the restoration.

Data sharing statement provided by the authors is available with the full text of this article at jemds.com.

Financial or other competing interests: None.

Disclosure forms provided by the authors are available with the full text of this article at jemds.com.

\section{REFERENCES}

[1] Nam J, Tokutomi H. Using zirconia-based prosthesis in a complete-mouth reconstruction treatment for worn dentition with the altered vertical dimension of occlusion. J Prosthet Dent 2015;(113):81-5.

[2] Shetty R, Shoukath S, Shetty NHG, et al. A novel design modification to improve flexural strength of zirconia framework: a comparative experimental in vitro study. J Pharm Bioall 2020;12(Suppl 1):S495-503.

[3] Tuntiprawon M, Wilson PR. The effect of cement thickness on the fracture strength of all-ceramic crowns. Aust Dent J 1995;40(1):17-21.

[4] Felton DA, Kanoy BE, Bayne SC, et al. Effect of in vivo crown margin discrepancies on periodontal health. J Prosthet Dent 1991;65(3):357-64.

[5] Jacobs MS, Windeler AS. An investigation of dental luting cement solubility as a function of the marginal gap. J Prosthet Dent 1991;65(3):436-42.

[6] Ji MK, Park JH, Park SW, et al. Evaluation of marginal fit of 2 CAD-CAM anatomic contour zirconia crown systems and lithium disilicate glass-ceramic crown. J Adv Prosthodont 2015;7(4):271-7.

[7] May KB, Russell MM, Razzoog ME, et al. Precision of fit: the procera allceram crown. J Prosthet Dent 1998;80(4):394404.

[8] Weaver JD, Johnson GH, Bales DJ. Marginal adaptation of castable ceramic crowns. J Prosthet Dent 1991;66(6):747-53.

[9] Bailey JH, Donovan TE, Preston JD. The dimensionsal accuracy of improved dental stone, silverplated and epoxy resin die materials. J Prosthet Dent 1988;59(3):307-10.

[10] Bindl A, Mormann WH. Marginal and internal fit of allceramic CAD/CAM crown-copings on chamfer preparations. J Oral Rehabil 2005;32(6):441-7.

[11] McLean JW, Von Fraunhofer JA. The estimation of cement film thickness by an in vivo technique. $\mathrm{Br}$ Dent J 1971;131(3):107-11.

[12] Kunii J, Hotta Y, Tamaki Y, et al. Effect of sintering on the marginal and internal fit of CAD/CAM-fabricated zirconia frameworks. Dent Mater J 2007;26(6):820-6.

[13] Willer J, Rossbach A, Weber HP. Computer-assisted milling of dental restorations using a new CAD/CAM data acquisition system. J Prosthet Dent 1998;80(3):346-53.

[14] Nakamura T, Dei N, Kojima T, et al. Marginal and internal fit of Cerec 3 CAD/CAM all-ceramic crowns. Int J Prosthodont 2003;16(3):244-8.

[15] Kokubo Y, Nagayama Y, Tsumita M, et al. Clinical marginal and internal gaps of in-ceram crowns fabricated using the GN-I system. J Oral Rehabil 2005;32(10):753-8.

[16] Pak HS, Han JS, Lee JB, et al. Influence of porcelain veneering on the marginal fit of digident and lava CAD/CAM zirconia ceramic crowns. J Adv Prosthodont 2010;2(2):33-8. 